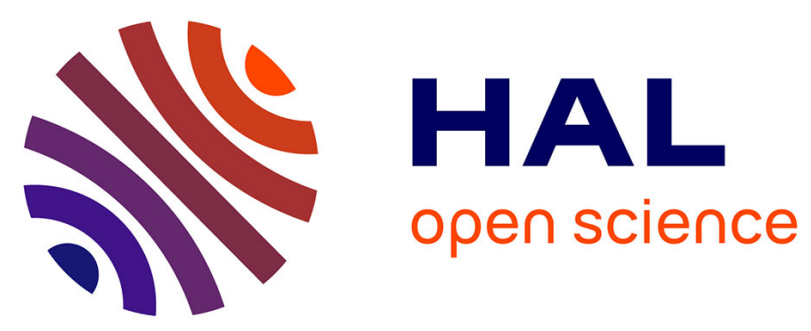

\title{
Description of fatigue damage in carbon black filled natural rubber
}

\author{
Jean-Benoit Le Cam, Bertrand Huneau, Erwan Verron
}

\section{To cite this version:}

Jean-Benoit Le Cam, Bertrand Huneau, Erwan Verron. Description of fatigue damage in carbon black filled natural rubber. Fatigue and Fracture of Engineering Materials and Structures, 2008, 31 (12), pp.1031-1038. 10.1111/j.1460-2695.2008.01293.x . hal-01006723

\section{HAL Id: hal-01006723 \\ https://hal.science/hal-01006723}

Submitted on 27 Sep 2017

HAL is a multi-disciplinary open access archive for the deposit and dissemination of scientific research documents, whether they are published or not. The documents may come from teaching and research institutions in France or abroad, or from public or private research centers.
L'archive ouverte pluridisciplinaire HAL, est destinée au dépôt et à la diffusion de documents scientifiques de niveau recherche, publiés ou non, émanant des établissements d'enseignement et de recherche français ou étrangers, des laboratoires publics ou privés. 


\title{
Description of fatigue damage in carbon black filled natural rubber
}

\author{
J.-B. LE CAM ${ }^{1}$, B. HUNEAU ${ }^{2}$ and E. VERRON ${ }^{2}$ \\ ${ }^{1}$ Laboratoire de Mécanique et Ingénieries, IFMA/UBP, BP 265, 63175 Aubière cedex, France, ${ }^{2}$ Institut de Recherche en Génie Civil et Mécanique, \\ UMR CNRS 6183, Ecole Centrale de Nantes, BP 92101, 44321 Nantes cedex 3, France
}

ABSTRACT The present paper describes macroscopic fatigue damage in carbon black-filled natural rubber (CB-NR) under uniaxial loading conditions. Uniaxial tension-compression, fully relaxing uniaxial tension and non-relaxing uniaxial tension loading conditions were applied until sample failure. Results, summarized in a Haigh-like diagram, show that only one type of fatigue damage is observed for uniaxial tension-compression and fully relaxing uniaxial tension loading conditions, and that several different types of fatigue damage take place in non-relaxing uniaxial tension loading conditions. The different damage types observed under non-relaxing uniaxial tension, loading conditions are closely related to the improvement of rubber fatigue life. Therefore, as fatigue life improvement is classically supposed to be due to strain-induced crystallization (SIC), a similar conclusion can be drawn for the occurrence of different types of fatigue damage.

Keywords crack growth; elastomer; fatigue damage; strain-induced crystallization.

NOM E N C A T URE $\begin{aligned} \varepsilon & =\text { nominal strain } \\ \varepsilon_{\text {mean }}, \varepsilon_{\text {ampl }}, \varepsilon_{\min }, \varepsilon_{\max } & =\text { mean, amplitude, minimum, maximum of nominal strain } \\ R & =\text { loading ratio in terms of strain } \varepsilon_{\min } / \varepsilon_{\max } \\ f & =\text { loading frequency } \\ N_{i} & =\text { life to crack initiation } \\ N_{f} & =\text { number of cycles to fracture }\end{aligned}$

\section{INTRODUCTION}

Elastomers are extensively used in industrial applications because of their large elastic deformation and great damping capabilities. Elastomeric parts, such as tires, seals, engine mounts, are often subjected to cyclic loading conditions in service. Thus, the study of fatigue characteristics of rubber is of major importance for both design and maintenance of structures.

Research works dealing with fatigue of elastomers have been carried out since the $1940 \mathrm{~s}$. Cadwell et al. ${ }^{1}$ proposed the first published study in which the surprising response of crystallisable elastomers was highlighted: authors show that natural rubber exhibits an improvement of its fatigue life under non-relaxing uniaxial tension loading conditions, i.e. without complete unloading of the sample during fatigue tests. This result was first presented

Correspondance: Jean-Benoît Le Cam. E-mail: lecam@ifma.fr in a nominal strain versus end-of-life number of cycles diagram.

Since the end of the 1990s, number of studies dealing with fatigue of carbon black-filled natural rubber (CBNR) have been proposed. ${ }^{2-7}$ Similarly to Ref. [1], fatigue tests performed on CB-NR have revealed an improvement of the fatigue life under non-relaxing uniaxial tension loading conditions; this improvement is classically attributed to strain-induced crystallization (SIC). ${ }^{1,8}$ Firstly considered for elastomers fatigue by André et al., ${ }^{2}$ the Haigh diagram is the most appropriate tool to exhibit fatigue life improvement, i.e. the influence of minimum strain on fatigue life. Even if it was first defined in terms of Cauchy stress, it is nowadays commonly admitted that fatigue life (end-of-life number of cycles) can be plotted as a function of numerous other mechanical variables such as stretch or strain, strain energy density, etc. However, most of studies dealing with fatigue life only consider one of these continuum mechanics variables without examining the nature of fatigue damage observed at different 
locations in the Haigh diagram, i.e. for different cyclic loading conditions.

The present paper is dedicated to the macroscopic description of fatigue damage in CB-NR under various uniaxial loading conditions. Thus, we propose to describe fatigue damage in CB-NR diabolo samples and to study the influence of SIC on the end-of-life. Different loading conditions (different minimum and maximum strain levels) will be investigated and results will be presented with the help of a Haigh-like diagram.

In the following, experimental details are first described: material, sample geometry, fatigue loading conditions and end-of-life criterion. Then, results are presented by distinguishing fatigue damage observed for three types of cyclic loading conditions. Results are summarized in a Haigh-like diagram in order to relate fatigue damage with loading conditions. After a brief discussion, a conclusion closes the paper.

\section{DESCRIPTION OF EXPERIMENTS}

\section{Material and samples}

The material considered here is a $34 \mathrm{phr}$ [parts per hundred of rubber (in weight)] CB-NR. Table 1 summarizes its chemical composition and Table 2 gives some basic mechanical characteristics. The geometry of the samples is similar to the one proposed by Beatty (see Fig. 6 p. 1352 in Ref. [9]); it is axisymmetric and usually referred to as 'diabolo' or 'dumbbell of revolution' sample. It is shown in Fig. 1; relevant terms for the following description of

Table 1 Chemical composition of the natural rubber (phr)

\begin{tabular}{ll}
\hline Ingredients & phr \\
\hline NR & 100 \\
Zinc oxide & 9.85 \\
Plastificant & 3 \\
Carbon black & 34 \\
Sulphur & 3 \\
Stearic acid & 3 \\
Antioxidant & 2 \\
Accelerators & 4 \\
\hline
\end{tabular}

Table 2 Some of basic mechanical properties

Properties

Density $\left(\mathrm{g} / \mathrm{cm}^{3}\right)$

Hardness (Shore A)

Failure stress $(\mathrm{MPa})$

Failure stretch (\%)

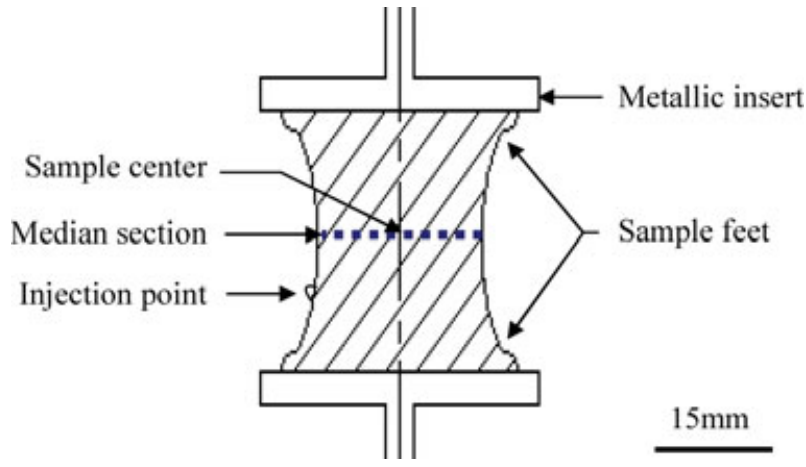

Fig. 1 Diabolo sample.

fatigue damage are detailed in this figure: the sample feet correspond to small radius of curvature zones which are favourable to strain and stress localization, the sample centre is defined as the intersection between the median section and the sample axis. Samples are obtained by injection moulding and rubber is adherized on metallic inserts, the compound is cured during $7 \mathrm{~min}$ and the mould temperature is set to $160^{\circ} \mathrm{C}$. Moreover, in order to overcome ageing problems, samples are frozen at $-18{ }^{\circ} \mathrm{C} 48 \mathrm{~h}$ after their moulding and they are thawed out $24 \mathrm{~h}$ before testing.

Such a sample is designed to induce uniaxial deformation in its median section under both tensile and compressive loading conditions. Nevertheless, due to its specific geometry, it also induces complex multiaxial deformation especially in the neighbourhood of metallic inserts. In this way, this specimen can be considered as a structure and then may exhibit several types of fatigue damage.

\section{FATIGUE-LOADING CONDITIONS}

Before detailing fatigue-loading conditions, it is first necessary to introduce relevant variables. Experiments are conducted under sinusoidal prescribed displacement. Thus, the uniaxial strain is

$\varepsilon(t)=\varepsilon_{\text {mean }}+\varepsilon_{\text {ampl }} \sin \left(\frac{2 \pi}{f} t\right)$.

$\varepsilon$ is the nominal strain, it is equal to the ratio between the displacement of the moving grip and the initial length of the specimen. Therefore, the minimum and maximum strain during cycles are:

$\varepsilon_{\text {min }}=\varepsilon_{\text {mean }}-\varepsilon_{\text {ampl }} \quad$ and $\quad \varepsilon_{\max }=\varepsilon_{\text {mean }}+\varepsilon_{\text {ampl }}$

and the loading strain ratio $R$ is defined by $\varepsilon_{\min } / \varepsilon_{\max }$.

Table 3 summarizes the different values of this ratio in regards to the type of cyclic loading conditions. Here, only three of the seven possible types of loading 
Table 3 Different types of cyclic loading conditions

\begin{tabular}{ll}
\hline Uniaxial cyclic loading conditions & $R$ \\
\hline Non-relaxing tension & ] $0,1[$ \\
Fully relaxing tension & 0 \\
Tension-compression $\left|\varepsilon_{\max }\right|>\left|\varepsilon_{\min }\right|$ & ]$-1,0[$ \\
Symmetric tension-compression & -1 \\
Tension-compression $\left|\varepsilon_{\max }\right|<\left|\varepsilon_{\min }\right|$ & ]$-\infty,-1[$ \\
Fully relaxing compression & $-\infty$ \\
Non-relaxing compression & ] $1,+\infty[$ \\
\hline
\end{tabular}

conditions were considered in this study: uniaxial tensioncompression $(R \in]-1,0[)$, fully relaxing uniaxial tension $(R=0)$ and non-relaxing uniaxial tension $(R \in$ ]0, 1[) loading conditions. In the following, these loading conditions will simply be described by the corresponding loading strain ratio $R$. Two parameters chosen into $\varepsilon_{\text {mean }}, \varepsilon_{\text {ampl }}, \varepsilon_{\min }, \varepsilon_{\max }$ and $R$, and the frequency are needed to completely describe loading conditions; in this study every loading cases will be defined in terms of $\varepsilon_{\min }$ and $R$. Fatigue tests were performed in the Trelleborg french Laboratory in a temperature room regulated at $23{ }^{\circ} \mathrm{C} .{ }^{4}$ The strain rate was set to limit the rise of temperature at the sample surface under $20^{\circ} \mathrm{C}$ in order to not superimpose thermal damage to mechanical damage; it corresponds to loading frequencies below $5 \mathrm{~Hz}$. No more details concerning sample dimensions and loading conditions can be given here because of industrial confidentiality.

\section{EXPERIMENTAL MEASUREMENT OF THE END-OF-LIFE}

Two different approaches are classically considered to experimentally determine the end-of-life of samples. Some authors consider that the end-of-life is defined by the number of cycles $N_{\mathrm{r}}$ necessary to break down the sample. ${ }^{1,10}$ Others define it by the number of cycles $N_{\text {i }}$ necessary to induce a self-initiated fatigue crack at sample surface. ${ }^{11,12}$ In the latter case, the length of the crack is arbitrarily determined: it depends on sample geometry and size and it is classically related to a significant decrease of sample stiffness. In the present paper, we adopt the second approach by considering the experimental end-of-life measurement recently proposed by OstojaKuczynski et al.: $:^{13}$ it consists of measuring the sample stiffness and correlating the significant decrease of this stiffness with the occurrence of a $2 \mathrm{~mm}$ length fatigue crack at sample surface. Practically, each fatigue test is carried out until sample fracture and both $N_{\mathrm{r}}$ and $N_{\mathrm{i}}$ are recorded.

\section{RES ULTS}

The aim of the present work is to relate the macroscopic fatigue damage to loading conditions, i.e. $\varepsilon_{\min }$ and $R$. Thus, before presenting our results, it is necessary to precisely define the three different types of cracks that are observed (see Fig. 1 for the description of sample zones):

- a large external crack in the median section,

- small external cracks at sample feet,

- cohesive internal crack just below metallic inserts.

In the following, fatigue damage types are presented depending on cyclic loading conditions. Firstly, fatigue damage induced by both $R \in]-1,0[$ and $R=0$ conditions is described, then fatigue damage induced by $R \in] 0,1[$ condition is investigated.

\section{UNIAXIAL TENSION-COMPRESSION $(R \in]-\infty, 0[)$ AND FULLY RELAXING UNIAXIAL TENSION $(R=0)$ LOADING CONDITIONS}

Only one type of fatigue damage is observed for both $R \in$ ] $-1,0$ [ and $R=0$ conditions. It corresponds to initiation and propagation of an external self-initiated crack at the surface of the median section. This crack propagates through the median section until sample failure. This is the type of damage that received the most attention in the recent literature. ${ }^{14,15}$ Fatigue damage types being identical for both $R \in]-1,0$ [ and $R=0$ conditions indicates that compression loading has no effect on fatigue damage. In the following, it is referred to as damage type (1). Fig. 2 presents the fracture surface corresponding to damage type (1). As shown in this figure, a round small surface takes place above the injection point. This zone

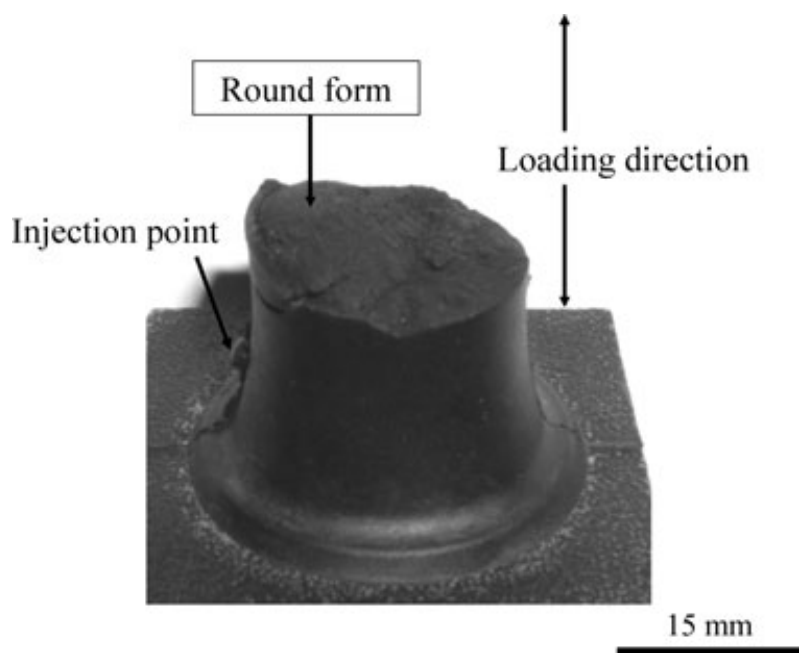

Fig. 2 Fatigue damage type (1). 
does not systematically contain the crack initiation zone. So, the crack propagates circumventing the zone above the injection point. It suggests that the zone surrounding the injection point has a different microstructure than the bulk material leading to different mechanical properties. The influence of the injection point was already observed by Robisson ${ }^{14}$ in Styrene Butadiene Rubber.

Finally, it is to note that for high maximum strain level $\left(\varepsilon_{\max }>200 \%\right)$ even if a crack propagates in the centre of the samples, they broke down due to the growth of small cohesive internal cracks below metallic inserts. This type of fatigue damage being rather observed for non-relaxing loading conditions, it will be investigated in the following section and referred to as fatigue damage type (2).

\section{NON-RELAXING UNIAXIAL TENSION $(R \in]$, 1[) LOADING CONDITIONS}

Fatigue tests performed with $R \in$ ]0, 1 [ classically exhibit fatigue life improvement in elastomers, which crystallize under deformation. This case should be thoroughly examined as we are convinced that the determination of the corresponding damage types will provide relevant information for the understanding of fatigue life improvement. Results obtained for $R \in$ ]0, 1 [ reveal several different damage types. Firstly, each fatigue damage type is described. Secondly, all damage types are related to the corresponding loading conditions in a Haigh-like diagram.

- Fatigue damage type (2): Sample failure is due to internal cracking below the metallic insert located on the side of the injection point. However, cutting performed in the neighbourhood of the opposite metallic insert also reveals internal cracks, but smaller and fewer than in the neighbourhood of the former one. Fig. 3 shows some of these internal cracks which grow, coalesce and finally produce a single circular front. This front propagates until sample failure. Failure is first cohesive then it becomes adhesive: the interface between elastomer and the metallic insert is broken down. Basic finite element computations demonstrate that areas located under metallic inserts are subjected to high negative hydrostatic pressure. It can be concluded that these internal cracks initiate due to cavitation; as previously observed in experiments conducted on 'pancake' samples ${ }^{16,17}$. It is to note that an external crack propagates in the median section (similarly to damage type (1) without leading to sample fracture.

- Fatigue damage type (3): Samples fail due to the propagation of an external crack in the median section. The corresponding fracture surface is located near sample centre on the side of the injection point. Moreover, cutting in the vicinity of metallic inserts reveals internal cracks, which distinguishes this damage type from damage type (1).

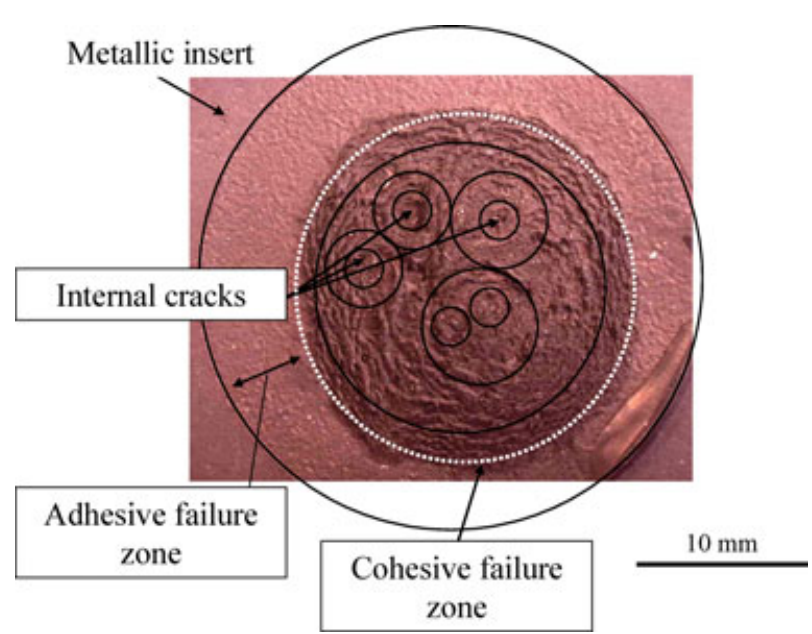

Fig. 3 Nucleation, growth and coalescence of cavities in the bulk material below the metallic inserts. The single circular propagation front cause the final adhesive rupture.

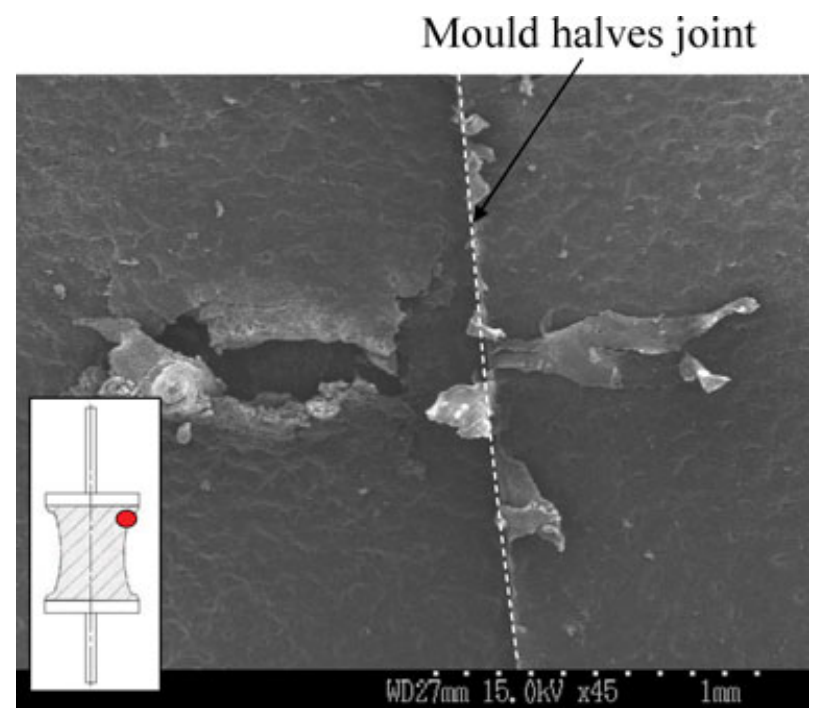

Fig. 4 Small crack at the sample feet obtained under non-relaxing uniaxial tension loading condition.

- Fatigue damage type (4): Numerous small external cracks are observed on sample surface in the vicinity of sample feet. They are more numerous on the opposite side of the injection point. One of these cracks in shown in Fig. 4. These small cracks do not propagate in the bulk material. Finally, cutting samples closed to metallic inserts also reveals internal cracks. In this case, fatigue tests were stopped beyond one million of cycles.

The following fatigue damage types are different than the above-mentioned ones: they exhibit branching, i.e. external cracks do not propagate in the median section of the sample but bifurcate. In the following, these cracks are called branching cracks. ${ }^{18,19}$ 
Fig. 5 Fatigue damage type (5) (non-relaxing uniaxial tension loading condition: (a) schematic view; (b) top view of encircled zone in Fig. 5(a).

- Fatigue damage type (5): This damage type is characterised by small external cracks similar to those of damage type (4) and a branching crack, which propagates from the neighbourhood of the metallic insert to the median section (see Fig. 5(a)). Cutting the broken sample below the metallic insert reveals small cohesive internal cracks as observed in damage type (4) (see Fig. 5(b)).

- Fatigue damage type (6): Sample failure is due to the propagation of internal cracks closed to one of the metallic inserts. Only three samples were tested: two of them revealed a branching crack in sample centre.

- Fatigue damage type (7): This type is similar to damage type (5): both internal cracks under metallic inserts and a central branching crack develop. But in this case, sample failure is due to the branching crack as shown in Fig. 6.

The seven types of fatigue damage observed in a Diabolo sample under uniaxial loading conditions are summarized

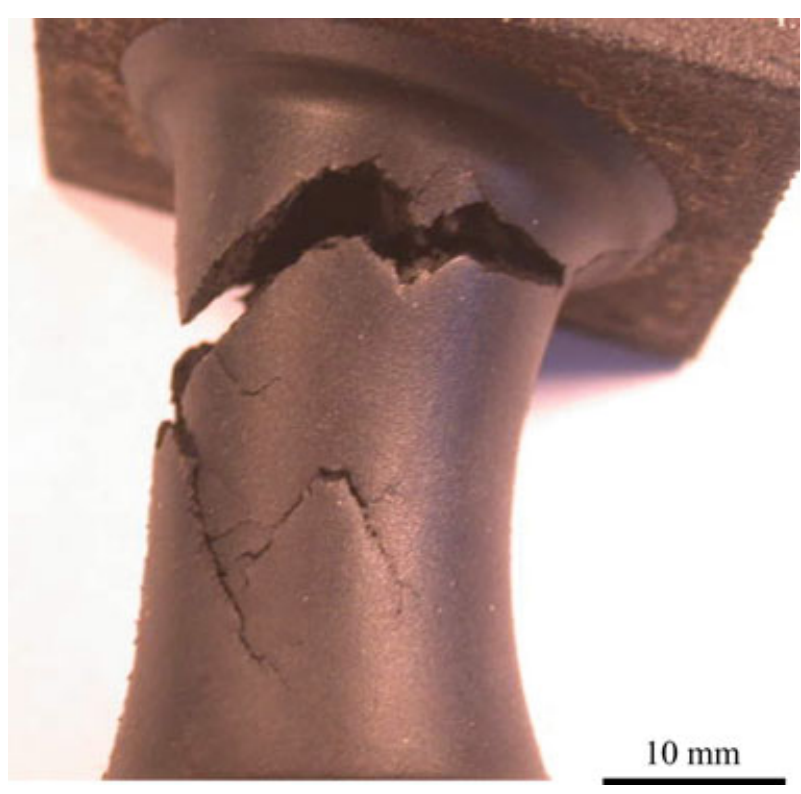

Fig. 6 Branching in the centre of the sample (non-relaxing uniaxial tension loading condition). in Table 4. Moreover, they are related to loading conditions in the Haigh-like diagram presented in Fig. 7. As fatigue tests were performed under prescribed displacement conditions, the $\mathrm{x}$-axis represents the mean strain $\varepsilon_{\text {mean }}$ and the $y$-axis represents the amplitude of strain $\varepsilon_{\text {ampl }}$ (due to confidentiality, no numerical values are given); for each loading condition, the corresponding fatigue damage type is plotted.

\section{DISCUSSION}

In order to discuss the previous 'cartography of damage', the Haigh-like diagram is split into three zones and the lines representing constant values of both $\varepsilon_{\min }$ and $\varepsilon_{\max }$ are drawn in Fig. 8.

- Zone I corresponds to $\varepsilon_{\min } \leq 0$ and low values of $\varepsilon_{\max }$. In this zone, only fatigue damage type (1) is observed. It can be concluded that for such values of $\varepsilon_{\max }$ (i) compression has no effect on fatigue damage and (ii) the negative hydrostatic pressure under the metallic inserts is not sufficient to induce cavitation.

- For higher values of $\varepsilon_{\max }$ and $R=0$, only one loading condition was investigated. It leads to fatigue damage type (2). Such values of $\varepsilon_{\max }$ increases the negative hydrostatic pressure which produces cavitation below metallic inserts. In our opinion, this result might be extended to the case where $R<0$.

The two other zones correspond to non-relaxing uniaxial tension, i.e. $\varepsilon_{\min }>0$.

- Zone II corresponds to low values of $\varepsilon_{\min }$. In this case there is a competition between high uniaxial stress level at the tip of the median crack and high negative hydrostatic pressure under metallic inserts. For lower values of $\varepsilon_{\text {max }}$, cavitation leads to sample fracture (zone II, damage type (2)) whereas higher values of $\varepsilon_{\max }$ promote the propagation of the median crack until failure (zone II, damage type (3)). 
Table 4 Summary of the seven types of fatigue damage at the macroscopic scale

\begin{tabular}{llll}
\hline $\begin{array}{l}\text { Fatigue damage } \\
\text { type }\end{array}$ & $\begin{array}{l}\text { Large external crack at the surface } \\
\text { median section }\end{array}$ & $\begin{array}{l}\text { Small external cracks } \\
\text { at sample feet }\end{array}$ & Cohesive internal cracks just below metallic inserts \\
\hline (1) & Yes, propagates to sample failure & No & No \\
(2) & Yes & No & Yes, propagates to sample failure by decohesion be- \\
(3) & Yes, propagates to sample failure & No & Yes metallic insert and elastomer \\
(4) & No & Yes & Yes \\
(5) & Yes & Yes & Yes, propagates by branching until sample failure \\
(6) & Yes, propagates by branching & No & Yes, propagates to sample failure by decohesion be- \\
(7) & Yes, propagates by branching & No & Yes
\end{tabular}

${ }^{\mathrm{a}}$ Fatigue tests stopped before failure.

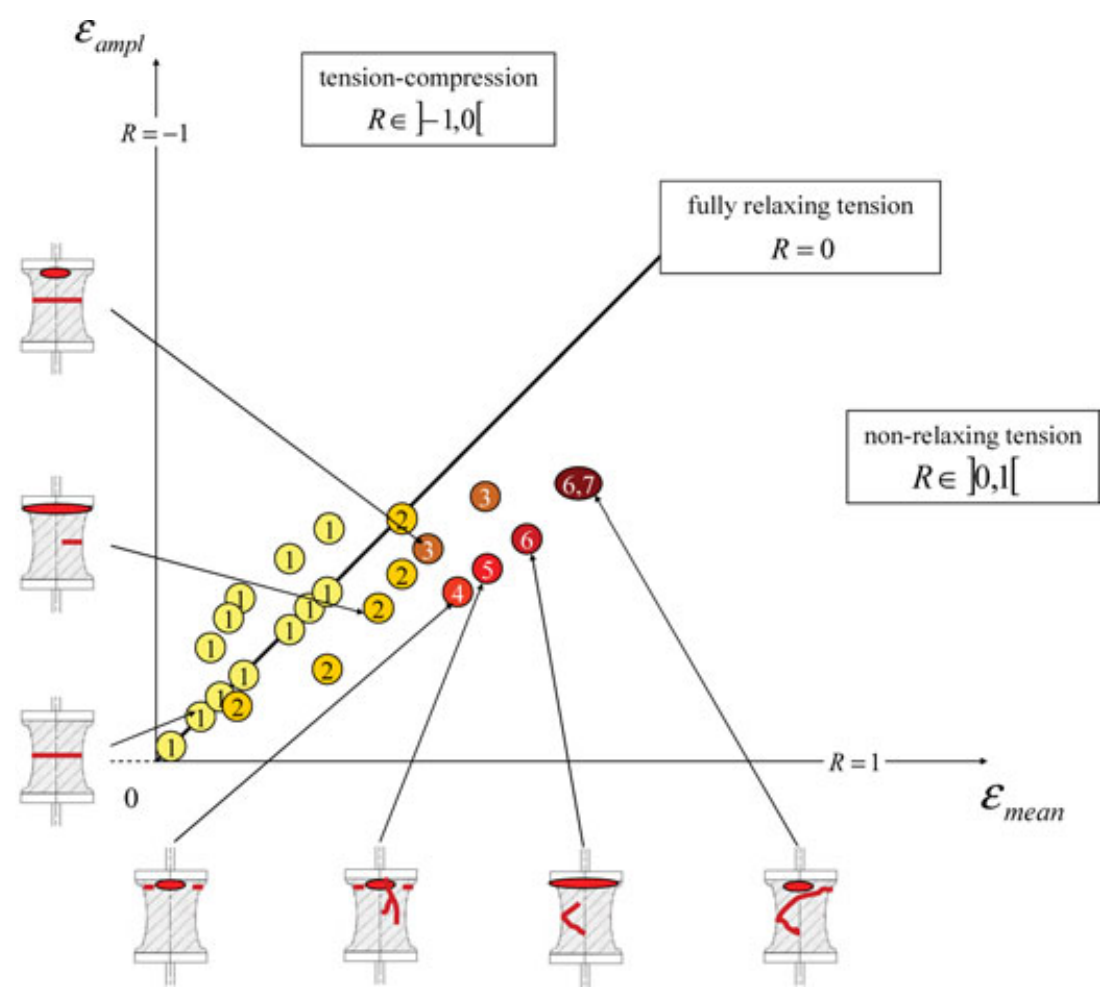

Fig. 7 Haigh diagram of uniaxial fatigue damage observed under prescribed displacement conditions.
- Zone III corresponds to high values of both $\varepsilon_{\min }$ and $\varepsilon_{\max }$. Two new phenomena are observed: occurrence of small surface cracks at sample feet (fatigue damage types (4) and (5)) and crack branching (fatigue damage types (5), (6) and (7)). Because the occurrence of small surface cracks at sample feet is due to the geometry of the samples and because theses crack never lead to sample failure, it is not relevant to comment this phenomenon here. Similarly to zone II, there is a competition between the propagation of small cavities below metallic inserts and the propagation of the median crack (damage types (6) and (7)). Nevertheless, the major difference lies in crack branching (bifurcation).
In order to explain above-mentioned differences between these three zones, one should invoke SIC in natural rubber. Several recent studies were devoted to the measurement of crystallinity by real-time X-ray diffraction technique during uniaxial cyclic tension (see for example Ref. [20] and Ref. [21]). The special case of CB-NR was investigated in Ref. [22]). The main results of these studies can be summarized as follow: (i) crystallization is activated when strain reaches a threshold level (around 75\% for a $50 \mathrm{phr}$ of carbon black at room temperature); (ii) crystallinity is approximately proportional to the strain; (iii) crystallinity decreases during unloading and all the 
Fig. 8 Magnification of the non-relaxing tension zone. 4 zones are delimited by $\varepsilon_{\min }=$ constant and $\varepsilon_{\max }=$ constant lines.

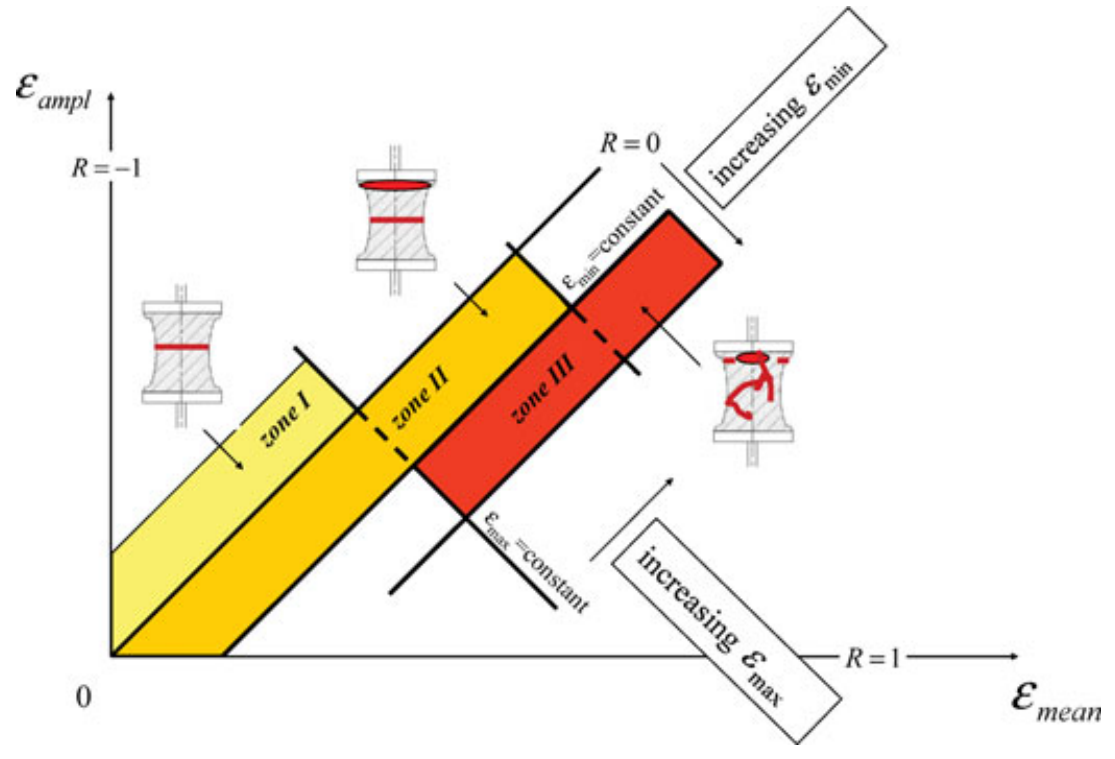

crystallites melt when strain reaches a threshold value; (iv) the volume of a crystallite being independent of strain, an increase of crystallinity corresponds to an increase of the number of crystallites.

- Zone I: $\varepsilon_{\min }$ being lower or equal to zero, at the end of each fatigue cycle all crystallites have disappeared (see (iii) above). Consequently, there is no accumulation of crystallites: the maximum number of crystallites reached in each cycle is constant, it only depends on the local maximum strain. Finally, the influence of SIC is very limited and it does not affect the crack location: the crack initiates in the median section of the sample and propagates perpendicularly to the loading direction.

- Zone II: in this case $\varepsilon_{\min }$ is greater than zero. After the initiation of the median crack, the crack tip zone is subjected to local strain assumed to be greater than the crystallinity threshold strain level even at the end of the cycle. Then, the crack tip is reinforced and the negative hydrostatic pressure below metallic inserts reaches a sufficiently high level to generate internal cracks by cavitation. These zones are also reinforced and a competition takes place between the propagation of the median crack and the propagation of internal cracks.

- Zone III: both $\varepsilon_{\min }$ and $\varepsilon_{\max }$ are high. Fatigue damage is located in the same areas of the sample than for zone II. Because of the high level of $\varepsilon_{\min }$ and the high strain level in the neighbourhood of flaws, the number of crystallites is larger than in the previous case; it induces crack branching either in the median section or below the inserts. Indeed, classical crack paths, i.e. in a plane normal to the loading direction, are not the ones which minimize energy requested for propagation.

\section{CONCLUSION}

This study investigates macroscopic fatigue damage in CB-NR under uniaxial loading conditions. Firstly, the results show that only one type of fatigue damage is observed for uniaxial tension-compression. Indeed, at the end of each fatigue cycle all crystallites disappeared (the strain level returns to zero) and the influence of SIC does not affect the crack location. Secondly, several different types of fatigue damage are observed for non-relaxing uniaxial tension loading conditions. For low levels of $\varepsilon_{\min }$, a competition takes place between high uniaxial stress level at the tip of the median crack and high negative hydrostatic pressure under metallic inserts. In fact, after the initiation of the median crack, the local strain level in the neighbourghood of the crack tip may remain greater than the strain level for which cristallinity disappears during the whole cycle. Then, the crack tip is reinforced and the negative hydrostatic pressure below metallic inserts reaches a sufficient level to induce internal cracks by cavitation. For high values of both $\varepsilon_{\min }$ and $\varepsilon_{\max }$, two new phenomena are observed: occurrence of small surface cracks at sample feet (due to sample geometry) and crack branching due to the presence of numerous crystallites. Finally, observing that different types of cyclic loading conditions lead to different types of fatigue damage in crystallizable rubbers indicates that the influence of loading conditions on the fatigue life should be discussed in regard to SIC.

\section{Acknowledgements}

Authors would like to acknowledge Allevard Rejna Autosuspensions for its financial support and the Trelleborg french Laboratory for having performed fatigue tests. 


\section{REFERENCES}

1 Cadwell, S. M., Merril, R. A., Sloman, C. M. and Yost, F. L. (1940) Dynamic fatigue life of rubber. Rubber Chem. Tech. 13, 304-315.

2 André, N., Cailletaud, G. and Piques, R. (1999) Haigh diagram for fatigue crack initiation prediction of natural rubber components. Kautsch. Gummi Kunstst. 52, 120-123.

3 Abraham, F., Alshuth, T. and Jerrams, S. (2001) The dependence of mean stress and stress amplitude of the fatigue life of elastomers. In: Proceedings of IRC 2001, Birminghan, UK.

4 Ostoja-Kuczynski, E. (2005) Comportement en fatigue des élastomères: application aux structures anti-vibratoires pour l'automobile, Ph.D. Dissertation, Ecole Centrale de Nantes, Nantes, France.

5 Saintier, N., Cailletaud, G. and Piques, R. (2006) Crack initiation and propagation under multiaxial fatigue in a natural rubber. Int. F. Fatigue 28, 61-72.

6 Mars, W. V. and Fatemi, A. (2003) Fatigue crack nucleation and growth in filled natural rubber. Fatigue Fract. Engng. Mater. Struct. 26, 779-789.

7 Harbour, R. J., Fatemi, A. and Mars, W. V. (2007) Fatigue crack growth of filled rubber under constant and variable amplitude loading conditions. Fatigue Fract. Engng. Mater. Struct. 30, 640-652.

8 Lindley, P. B. (1973) Relation between hysteresis and the dynamic crack growth resistance of natural rubber. Int. $\mathcal{F}$. Fracture 9, 449-462.

9 Beatty, J. R. (1964) Fatigue of rubber. Rubber Chem. Technol. 37, 1341-1364.

10 Roberts, B. J. and Benzies, B. J. (1977) The relationship between uniaxial and equibiaxial fatigue in gum and carbon black filled vulcanizates. In: Proceedings of Rubbercon'77', Vol. 2.1, pp. 2.1-2.13.

11 Mars, W. V. (2001) Multiaxial fatigue of rubber. Ph.D. Dissertation, University of Toledo, Toledo, OH, USA.
12 Mars, W. V. and Fatemi, A. (2002) A literature survey of fatigue analysis approaches for rubber. Int. F. Fatigue $\mathbf{2 4}$, 949-961.

13 Ostoja-Kuczynski, E., Charrier, P., Verron, E., Markmann, G., Gornet, L. and Chagnon, G. (2003) Crack initiation in filled natural rubber: experimental database and macroscopic observations. In: Constitutive models for rubber (Edited by A. Muhr, J. Busfield), A.A. Balkema Publishers, pp. 3-10.

14 Robisson, A. (2000) Comportement mécanique d'un élastomère chargé en silice. Etude de l'influence des charges et modélisation par une loi visco-hyperélastique endommageable. Ph.D. Dissertation, Ecole des Mines de Paris, Paris, France.

15 Wang, B., Lu, H. and Kim, G. (2002) A damage model for the. Fatigue life of elastomeric materials. Mech. Mater. 34, 475-483.

16 Gent, A. N. (1990) Cavitation in rubber: a cautionary tale. Rubber Chem. Technol. 63, G49-G53.

17 Legorju-Jago, K. and Bathias, C. (2002) Fatigue initiation and propagation in natural and synthetic rubbers. Int. F. Fatigue 24, 85-92.

18 Kim, H. J. and Hamed, G. R. (2000) On the reason that passenger tire sidewalls are based on blends of natural rubber and cis-polybutadiene. Rubber Chem. Technol. 73, 743-752.

19 Shaw, C. and Kerchman, V. (2003) Experimental study and finite element simulation of heat build-up in rubber compounds with application to fracture. Rubber Chem. Technol. 76, 386-405.

20 Toki, S., Fujimaki, T. and Okuyama, M. (2000) Straininduced crystallization of natural rubber as detected real-time by wide-angle X-ray diffraction technique. Polymer 41, 5423-5429.

21 Trabelsi, S., Albouy, P. A. and Rault, J. (2003) Crystallization and melting processes in vulcanized stretched natural rubber. Macromolecules 36, 7624-7639.

22 Trabelsi, S., Albouy, P. A. and Rault, J. (2003) Effective local deformation in stretched filled rubber. Macromolecules 36, 9093-9099. 